\title{
GAS-SOLID FLOW THROUGH EJECTOR
}

\author{
N. H. Mahmoud, Mofreh H. Hamed, A. A.Abdel-Hamied and A. A. Hussien \\ Mechanical Power Engineering Department, \\ Faculty of Engineering, Minoufiya University, Shebin El-kom, Egypt \\ E-mail: hamiedabdou@yahoo.com
}

\begin{abstract}
Single-phase (air-air) and two-phase (air-solid) flows through ejector are numerically and experimentally studied in this paper. The numerical model is performed using continuity equation for the gas phase and the solid phase separately, and the momentum equation for a homogenous mixture of gas-solid flow. The model takes into account the gas and solid friction with the wall and the drag force exerted on a particle by the gas. Three different geometries of the ejector are studied numerically and experimentally. The effects of the mixing chamber and tail pipe/diffuser, geometries on the ejector performance are studied. In addition, the effects of fluid motive pressure and the solid particle mass flow rate on the static pressure distribution are also studied. Comparisons are carried out between theoretical results and the present and published experimental data for the axial wall static pressure distribution. These comparisons show good agreements. The obtained results show that, geometry of convergent-constant-divergent of the mixing duct gives high vacuum pressure and preferable performance of the ejector.

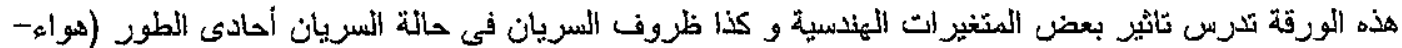

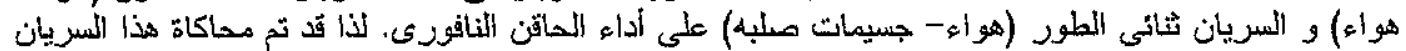

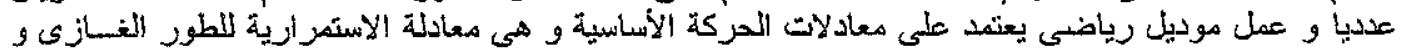

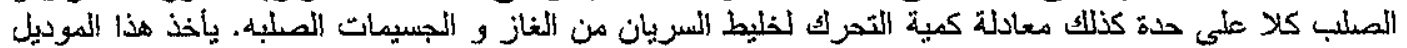

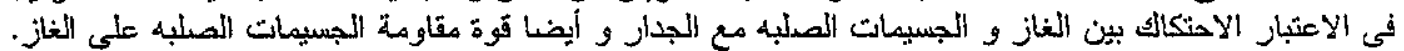

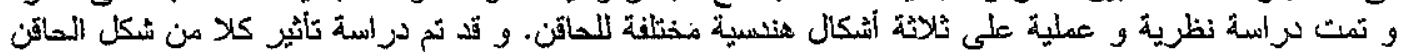

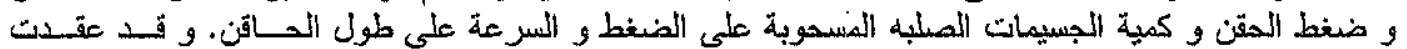

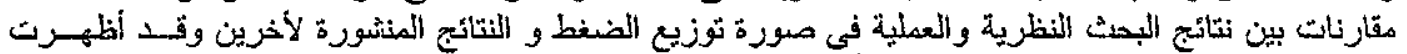

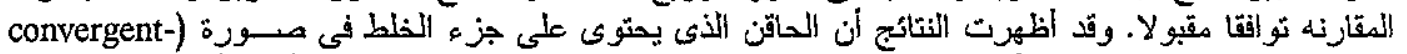
(constant-divergent Keywords: Ejector, Air-Air Ejector, Gas-Solid Ejector, Mixing Process, Performance
\end{abstract}

\section{1- INTRODUCTION}

The ejector is used in many fields for different purposes because its simple construction and facile operation. In general, the ejector has driving fluid with high pressure. The driving fluid flows through a motive nozzle to suck the fluid or solids. The two fluids are mixed in the mixing duct and then the mixture flows through the diffuser where the pressure recovery is occurred. Single-phase ejectors have been studied numerically and experimentally by many researchers [1-7]. Engel [1] studied theoretically the performance of single phase ejector. Several assumptions are taken into account to derive the equations which describe the main parameters of flow and ejector efficiency. Hedges and Hill [2], modelled and simulated a two-dimensional mixing of a compressible jet into a variable-area mixing duct for a wide range of Mach number, mass flow ratio and initial conditions. Their modelling and consequently simulation are based on mixing length approximation. Abou-Taleb [3] investigated analytically and experimentally the effect of the geometric parameters and flow conditions on the performance of single phase ejector. Hichman, et al. [4] performed an analytical model to predict the performance characteristics of axsymmetric singlenozzle jet pump in two-dimensional approximation with variable mixing area tubes. Fabri and Paulon [5] represented the theoretical and experimental studies on supersonic air to air ejectors. Sazbo [6] studied the influence of the gas parameters of the primary gas jet on the final vacuum created by a supersonic gas ejector. Hung et al.[7] performed an analysis of ejector performance for one dimensional flow. Several researches studied two-phase (gas-solid) ejectors [8,9]. Kovacs and Varadi [9], studied the tow-phase flow of air-solid suspension through a vertical tube. Chellapan and Ramaiyan [10] studied experimentally design parameters of a gas- solid ejector feeding and the effect of the suction position with respect to the motive jet on the ejector 
performance. Kmiec and Leschonski [11, 12] studied theoretically and experimentally a gas-solid injector performance. Therefore the main objective of the present study is to investigate theoretically and experimentally the effect of both ejector geometry and inlet flow conditions on the ejector performance for single phase (air-air) and two-phase (air-solid) ejector.

\section{2-EXPERIMENTAL SET-UP AND PROCEDURE}

An experimental setup is designed and constructed to study the effect of ejector geometry, inlet motive gas pressure and the presence of solid particles on the ejector performance. Figure (1) shows the schematic diagram of the experimental set-up. The suction or upstream section with $520 \mathrm{~mm}$ length and $54 \mathrm{~mm}$ diameter is made from prespix and connected to the solid feeding tank. The convergent-divergent nozzle (i.e. motive nozzle) is made from brass and it has 2 $\mathrm{mm}$ throat and $4 \mathrm{~mm}$ exit diameter. The mixing section has an inlet diameter of $54 \mathrm{~mm}$ and a length of $520 \mathrm{~mm}$. The mixing section is joined with a tail pipe or tail diffuser. The exit diameter of the tail diffuser is $105 \mathrm{~mm}$. The mixing and tail pipes are made from prespix. Both of upstream section and the motive nozzle are the same for the investigated three tested geometries while the mixing and tail parts are constructed with different geometries. The three mixing sections have the same total length as shown Figure (2).

The theoretical calculations and experimental results are carried out using sand as a solid material. Sand particles are sized experimentally. Average mean diameter of particles is about $300 \mu \mathrm{m}$. The mixing section for geometry-1, contains a constant duct with $540 \mathrm{~mm}$ length and $54 \mathrm{~mm}$ diameter and a tail pipe of $300 \mathrm{~mm}$ length. While geometry- 2 is a constant section connected with a tail diffuser and geometry-3 is consisted of a convergent-constant-divergent mixing sections with throat diameter of $30 \mathrm{~mm}$ and a tail diffuser.

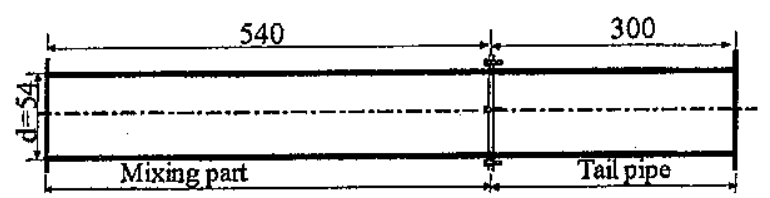

Geometry (1)
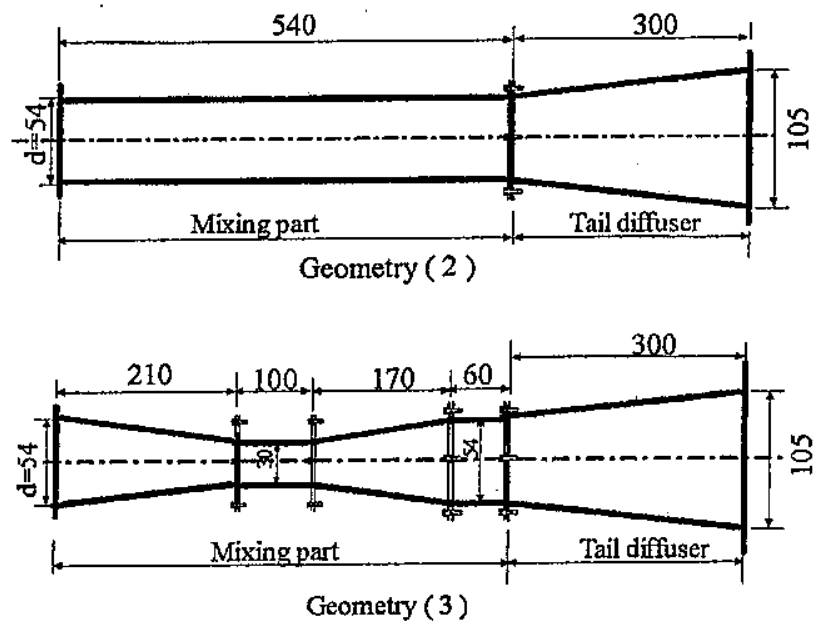

Figure (2) Investigated ejector geometries, (Dimensions in $\mathrm{mm}$ ).

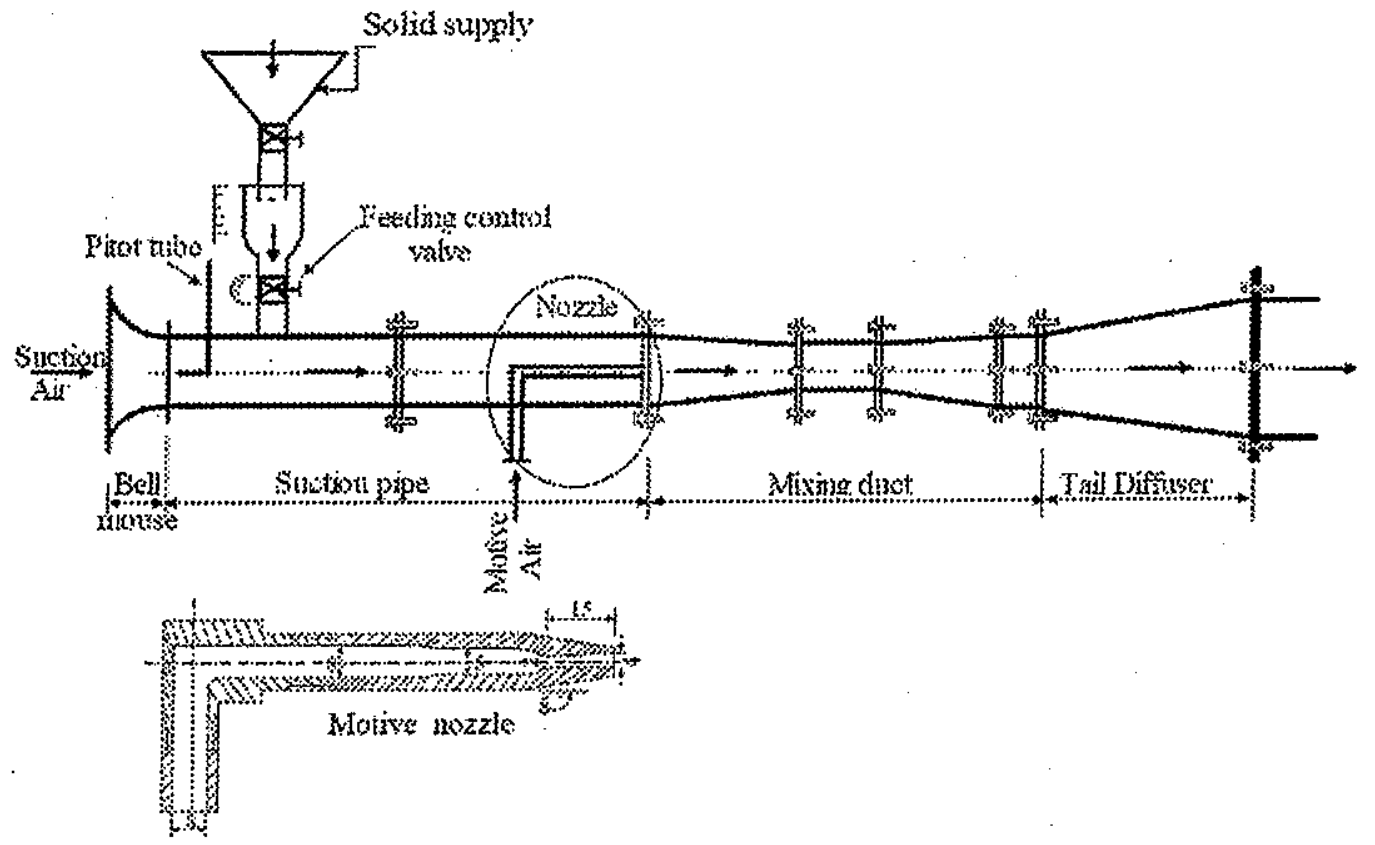

Figure (1) Layout of experimental set-up. 
Multi-tube water manometer is used to measure the wall axial static pressure differences. The measuring fluid is colored water. The manometer is connected to 22 pressure taps. The taps having $1 \mathrm{~mm}$ inner diameter and are drilled normal to the wall of the tested section. Pitot tube is used to measure the velocity at different points for a certain section as shown figure (1). The average velocity is calculated from the velocity distribution and it is used to calculate the inlet gas mass flow rate. The suction solid is collected during a certain time and weighted to determine the solid mass rate. The uncertainty for all the measuring devices is found to be in the range of $0.002 \%$ to $5.55 \%$.

\section{3- MATHEMATICAL MODEL}

The numerical calculations are performed by applying continuity and momentum equations as shown [11]. Theses equations are applied on the control volume as shown in Figure (3). The following assumptions are used to simulate the flow through ejector:

- Flow is one-dimensional,

- The flow is assumed isothermal,

- The solid particles are of spherical shape.

Based on these assumptions, the following are obtained:

\section{3 -1 Continuity Equation}

\section{3-1-1 Gas-phase}

The continuity equation states take the form,

$$
\frac{1}{\mathrm{v}_{\mathrm{g}}} \cdot \frac{\mathrm{dv}_{\mathrm{g}}}{\mathrm{dx}}+\frac{1}{\mathrm{~A}} \cdot \frac{\mathrm{dA}}{\mathrm{dx}}+\frac{1}{\varepsilon} \cdot \frac{\mathrm{d} \varepsilon}{\mathrm{dx}}=\frac{\dot{\mathrm{m}}_{\mathrm{j}}}{\dot{\mathrm{m}}_{\mathrm{g}} \Delta \mathrm{x}}
$$

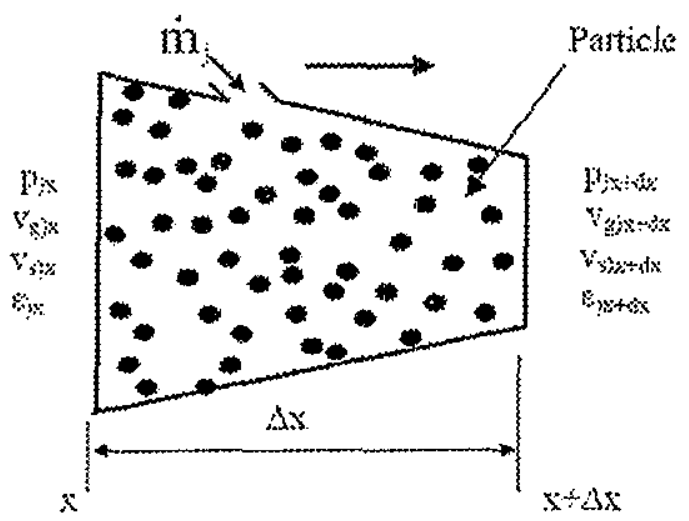

Figure (3) Control volume

\section{3-1-2 Solid-phase} yields to;

The continuity equation of the solid phase

$$
\frac{1}{v_{s}} \cdot \frac{d v_{s}}{d x}+\frac{l}{A} \cdot \frac{d A}{d x}+\frac{1}{(1-\varepsilon)} \cdot \frac{d \varepsilon}{d x}=0
$$

\section{3-2 Momentum Equation}

The momentum equation for a mixture of gassolid flow can be expressed by equating the rate of momentum change in the control volume plus the net efflux of momentum from the control volume with the net forces acting on the flow in the control volume. This equation can be expressed as, $\varepsilon \rho_{\mathrm{B}} \mathrm{v}_{\mathrm{B}} \frac{\mathrm{dv_{ \textrm {g } }}}{\mathrm{dx}}+(\mathrm{I}-\varepsilon) \mathrm{p}_{\mathrm{s}} \mathrm{v}_{\mathrm{s}} \frac{\mathrm{dv} s}{\mathrm{dx}}-\frac{\dot{\mathrm{m}}_{\mathrm{j}} \mathrm{u}_{\mathrm{j}}}{\mathrm{A} \Delta \mathrm{x}}+\frac{\mathrm{p}}{\mathrm{A}} \cdot \frac{\mathrm{dA}}{\mathrm{dx}}=\frac{\mathrm{dp}}{\mathrm{dx}}-F_{\mathrm{w}}-F_{\mathrm{p}}$

Where in equation $(3),\left(\dot{\mathrm{m}}_{\mathrm{j}} \mathrm{u}_{\mathrm{j}}\right)$ represents the mass source due to the injected (motive) gas.

Assuming that the pressure drop occurs only in the gaseous phase. Therefore,

$$
\rho_{\mathrm{s}} \mathrm{v}_{\mathrm{s}} \frac{\mathrm{dv} \mathrm{v}_{\mathrm{s}}}{\mathrm{dx}}=\mathrm{f}_{\mathrm{s}}-\frac{\mathrm{F}_{\mathrm{p}}}{1-\varepsilon}
$$

Friction force between the gas and the wall \{i.e., $F_{w}$ in equation (3)\} can be calculated as follows due to [8],

$\mathrm{F}_{\mathrm{w}}=\frac{\mathrm{f}_{\mathrm{g}} \varepsilon \rho_{\mathrm{g}} \mathrm{v}_{\mathrm{g}}^{2}}{2 \mathrm{~d}_{\mathrm{t}}}$

where $f_{g}$ is the gas friction coefficient and can be determined using an equation represented in [8] as,

$f_{\mathrm{g}}=0.316 \mathrm{Re}_{\mathrm{g}}^{-0.25}$

Here, $\operatorname{Re}_{\mathrm{g}}$ is the gas Reynolds number and defined as,

$\operatorname{Re}_{\mathrm{g}}=\frac{v_{\mathrm{g}} d_{\mathrm{t}} \rho_{\mathrm{g}}}{\eta} \quad$ where, $\eta$ is the gas viscosity.

$F_{p}$ is the solid particle-wall friction, it can be calculated by due to [] ,

$$
F_{p}=\frac{f_{p}(1-\varepsilon) \rho_{s} v_{s}^{2}}{2 d_{t}}
$$

where $f_{p}$ is the particle friction coefficient and $f_{s}$ is the drag force exerted by the gas on the solid per unit volume. Both $f_{p}$ and $f_{s}$ are obtained using correlations suggested in [8] and [13],

$$
\begin{aligned}
& \mathrm{f}_{\mathrm{p}}=\frac{\mathrm{v}_{\mathrm{s}}(\mathrm{t})}{\mathrm{v}_{\mathrm{s}}(\mathrm{t}-\Delta \mathrm{t})} \cdot \frac{1}{217(1-\varepsilon)+1} \times \\
& \left\{3 . 1 3 * 1 0 ^ { 5 } \mathrm { Ga } ^ { 0 . 2 5 } \left(\mathrm{Si}^{0.5} \mathrm{Fr}_{\mathrm{p}}^{-0.25} \mathrm{Ga}^{0.1} \mathrm{DR}\right.\right. \\
& \left.\left.+1.55^{*} 10^{-3} \mathrm{Fr}_{\mathrm{g}}^{0.5}\right)\right\} \\
& \mathrm{f}_{\mathrm{s}}=\frac{3}{4} \mathrm{C}_{\mathrm{DS}} \cdot \frac{\rho_{\mathrm{g}} \mathrm{v}_{\mathrm{r}}\left|\mathrm{v}_{\mathrm{r}}\right|}{\mathrm{d}_{\mathrm{p}}}
\end{aligned}
$$

where $C_{D S}$ is solid drag coefficient, and can be calculated using the following correlations [13],

$$
\begin{array}{ll}
C_{D S}=\frac{24}{\operatorname{Re}_{s}} & \text { for } \operatorname{Re}_{\mathrm{s}}<1.0 \\
C_{D S}=\frac{24}{\operatorname{Re}_{\mathrm{s}}}\left(1+0.15 \operatorname{Re}_{\mathrm{s}}^{0.687}\right) & \text { for } 1<\operatorname{Re}_{\mathrm{s}}<1000 \\
C_{D S}=0.44 & \text { for } \operatorname{Re}_{\mathrm{s}}>1000
\end{array}
$$


where $\operatorname{Re}_{\mathrm{s}}$ is the Reynolds number for the solid particles and is defined by,

$$
\operatorname{Re}_{\mathrm{s}}=\frac{\rho_{\mathrm{g}} \mathrm{d}_{\mathrm{p}}\left|\mathrm{v}_{\mathrm{g}}-\mathrm{v}_{\mathrm{s}}\right|}{\eta}
$$

\section{3-3 The Dimensionless Forms}

The system of equations (1) to (9) can be rewritten in a dimensionless form. Therefore, a new set of dimensionless equations should be derived. This is carried out by introducing the following dimensionless quantities:

$$
\begin{aligned}
& \bar{v}_{\mathrm{s}}=\frac{\mathrm{v}_{\mathrm{s}}}{\mathrm{v}_{\mathrm{s} 1}}, \quad \overline{\mathrm{v}}_{\mathrm{g}}=\frac{\mathrm{v}_{\mathrm{g}}}{\mathrm{v}_{\mathrm{g} 1}}, \quad \bar{\varepsilon}=\frac{\varepsilon}{\varepsilon_{1}}, \quad \tilde{\mathrm{x}}=\frac{\mathrm{x}}{\mathrm{L}}, \\
& \mathrm{s}=\frac{\mathrm{v}_{\mathrm{s} 1}}{\mathrm{v}_{\mathrm{g} 1}}, \quad \lambda=\frac{\rho_{\mathrm{s}}}{\rho_{\mathrm{gl}}}, \quad \mathrm{c}=\frac{\mathrm{p}_{1}}{\rho_{\mathrm{g} 1} \mathrm{v}_{\mathrm{g} 1}^{2}}
\end{aligned}
$$

The differential equations of gas velocity can be represented in dimensionless form as,

$\frac{d \bar{v}_{g}}{d \bar{x}}=\frac{A_{1}}{\bar{\varepsilon} \bar{p} A^{2}} \cdot \frac{d \bar{p}}{d \bar{x}}-\frac{A_{1}^{2}\left(1-\varepsilon_{1}\right)}{\varepsilon_{1} \bar{\varepsilon}^{2} \bar{p} A^{2} \bar{V}_{s}^{2}} \cdot \frac{d \bar{v}_{s}}{d \bar{x}} \times$

$\left[\frac{A_{1}}{A^{2} \bar{p} \bar{\varepsilon}}-\frac{\left(1-\varepsilon_{1}\right) A_{1}^{2}}{\varepsilon_{1} \bar{\varepsilon}^{2} \bar{p} A^{3} \bar{v}_{s}}\right] \frac{d A}{d \bar{x}}$

The solid velocity variation along the ejector can be illustrated as,

$$
\begin{aligned}
& \frac{d \bar{v}_{s}}{d \bar{x}}=G \frac{\bar{p} \bar{\varepsilon}^{-2.7}}{s^{2} \lambda \bar{v}_{s}}\left\{\left(v_{g 1} \bar{v}_{g}-v_{s I} \bar{v}_{s}\right) \times\right. \\
& \left.\left|\left(v_{g 1} \bar{v}_{g}-v_{s 1} \bar{v}_{s}\right)\right|\right\}-\frac{f_{p} s \bar{v}_{s} L}{2 d_{t}} \\
& \text { where } G=\frac{3 C_{D S} \varepsilon_{1}^{-2.7} L}{4 d_{p}}
\end{aligned}
$$

The pressure gradient can be formulated in dimensionless form as,

$\frac{\mathrm{d} \overline{\mathrm{p}}}{\mathrm{d} \overline{\mathrm{x}}}=\left\{\left(1-\varepsilon_{1}\right) \overline{\mathrm{p}}\left[\frac{\mathrm{A}_{1}^{3}}{\mathrm{~A}}-\lambda \mathrm{s}^{2} A \mathrm{~A}_{1} \overline{\mathrm{p}} \bar{\varepsilon}^{2} \overline{\mathrm{v}}_{\mathrm{s}}^{2}\right] \times\right.$

$\frac{d \bar{v}_{s}}{d \bar{x}}+A^{2} \bar{\varepsilon}^{2} \bar{p}^{2} \bar{v}_{s}^{2}\left[\frac{\left(1-\varepsilon_{1}\right) A_{1}^{3}}{\bar{p} \bar{\varepsilon}^{2} \overline{\mathbf{v}}_{s} A^{4}}-c \frac{\bar{p}}{A}+\right.$

$\frac{\dot{\mathrm{m}}_{\mathrm{j}} \mathrm{u}_{\mathrm{j}}}{\mathrm{A} \rho_{\mathrm{g}} \overline{\mathrm{v}}_{\mathrm{Bl}}^{2}}-\frac{\varepsilon_{\mathrm{l}} \mathrm{A}_{1}^{2}}{\bar{\varepsilon} \overline{\mathrm{p} A}} \cdot \frac{\mathrm{d}\left(\frac{1}{\mathrm{~A}}\right)}{\mathrm{d} \overline{\mathrm{x}}}-\frac{\mathrm{f}_{\mathrm{g}} \varepsilon_{1} \bar{\varepsilon} \overline{\mathrm{p}} \overline{\mathrm{v}}_{\mathrm{g}}^{2} \mathrm{~L}}{2 \mathrm{~d}_{\mathrm{t}}}-$

$\left.\left.\frac{f_{p} \lambda\left(1-\varepsilon_{l}\right) A_{1} s^{2} \bar{v}_{s} L}{2 d_{t} A}\right]\right\}\left[\bar{\varepsilon} \bar{v}_{s}^{2}\left(c A^{2} \bar{\varepsilon} \bar{p}^{2}-\right.\right.$

$\left.\varepsilon_{1} A_{1}^{2}\right]^{-1}$

\section{3-4 Numerical Technique}

The dimensionless equations (11), (12) and (13) are coupled and solved together along the ejector axis using fourth order Runge-Kutta scheme [14]. The numerical procedure depends upon the inlet conditions to calculate the gas and solid velocity and the axial static pressure distribution along the ejector. The convergence of solution achieved when the absolute difference between the static pressure at the ejector exit and the atmospheric pressure performed the following condition,

$$
\frac{\left|\mathrm{p}-\mathrm{p}_{\mathrm{atm}}\right|}{\mathrm{p}_{\mathrm{atm}}} \leq 0.001
$$

\section{4- MODEL VERIFICATION}

In order to validate the numerical model, the present predicted results for the pressure drop along ejector length are compared with published experimental and theoretical data. This comparison is shown in figure (4). The comparison between the present theoretical results with experimental data [4] in case of air-air flow is shown in figure (4) for two different values of mass ratio ( $\mu_{\mathrm{a}}=19.4$ and 23.6). In the numerical model, ejector geometry and position of injection are taken as reported in experimental work. Another comparison concerning theoretical and experimental results obtained for air-solid ejector [11] is shown in figure (5).

In the numerical model, liner gradual mixing has been observed between motive (i.e. the mass source term) and suction fluids. From figures (4 and 5) it can be observed that, there is a considerable agreement between present numerical results and other published data.

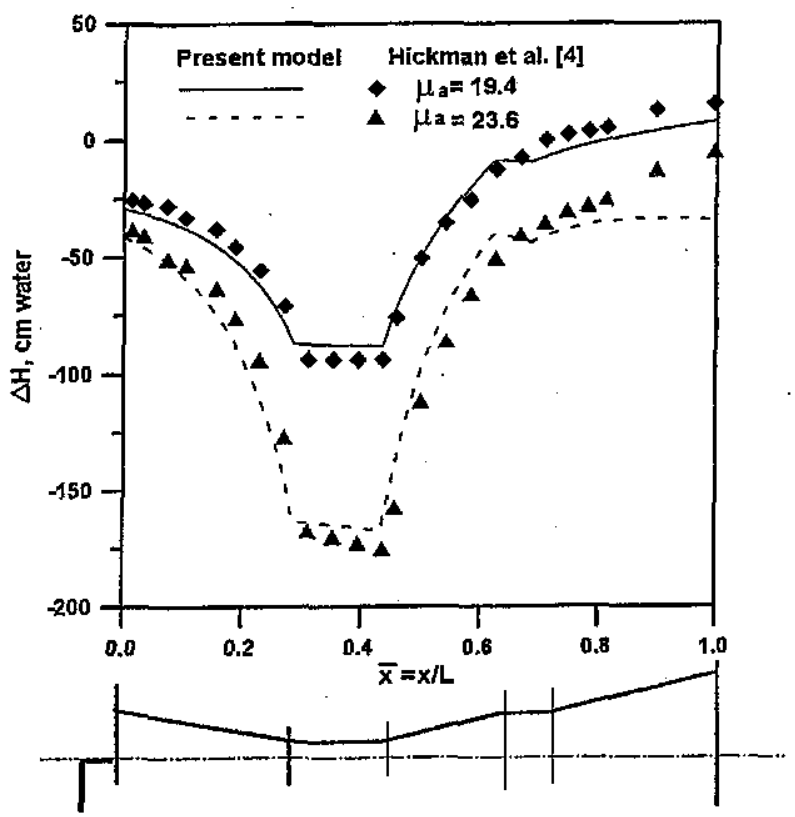

Figure (4) Comparison between the results obtained using the present model and experimental published data [4]. 


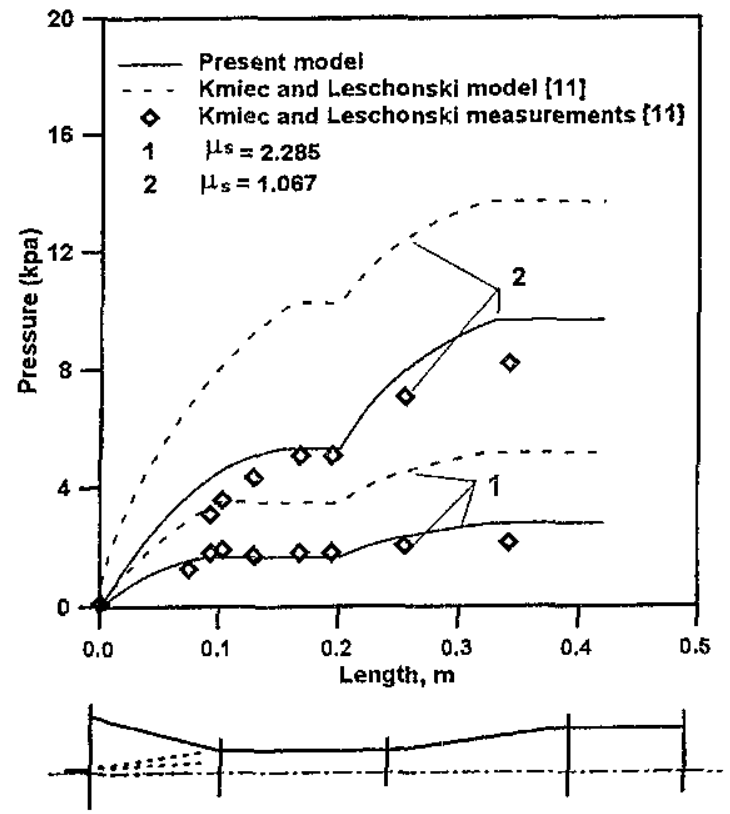

Figure (5) Comparison between the results obtained using the present model with theoretical and experimental data [11].

\section{5-EXPERIMENTAL AND THEORETICAL RESULTS}

Some of experimental data and theoretical calculations are performed to study the effects of both motive gas pressure and the solid mass flow rate on pressure distribution along ejector for each tested geometry. In the following, discussion of results is divided into three items concerning effects of ejector geometry, pressure of motive gas and rate of solids flow on the static pressure distribution along the tested ejector.

\section{1- Effect of Ejector Geometry:}

Figure (6) shows the change of the measured axial static pressure distribution along the axial length for the three tested geometries. Results of figure (6) are obtained at constant measured motive gas pressure $\left(p_{m}=7.0\right.$ bar) for air-air ejector. It can be seen from the figure that, geometry- 2 has the highest pressure difference through the suction part $(\Delta \mathrm{H}=-9$ $\mathrm{cm}$ water), but geometry-1 has the lowest pressure difference $(\Delta H=-5 \mathrm{~cm}$ water). In the mixing part, geometry-3 has the highest pressure difference compared with both geometry-1 and geometry-2. This behaviour reflects the effect of changing crosssection area of the mixing part and the interchange of momentum between injected and sucked flow. The pressure returns to decrease in the tail pipe of geometry-1 due to friction effect. Pressure recovery is occurred through the tail diffuser of both geometry-2 and geometry-3, where the pressure increases to reach the atmospheric pressure.
Figure (7) shows the change of the measured axial static pressure distribution along the axial length of the three tested geometries with air-solid flow. These distributions are carried out at constant motive gas pressure of 7.0 bar and a constant solid mass ratio $\left(\mu_{s}\right)$ of 3.0. It can be seen from this figure that, geometry- 3 has the maximum vacuum pressure at the mixing throat section. Whilst geometry-2 has the lowest pressure in the upstream section (suction part). Also from figure (7), it can be observed that the maximum vacuum pressure for geometry- 3 decreases from $-17 \mathrm{~cm}$ water for single phase flow (air-air) to $12.5 \mathrm{~cm}$ water for two-phase flow ( air-solid). The same effect due to the presence of solid for the geometry-2 and the geometry-1 is noticed.

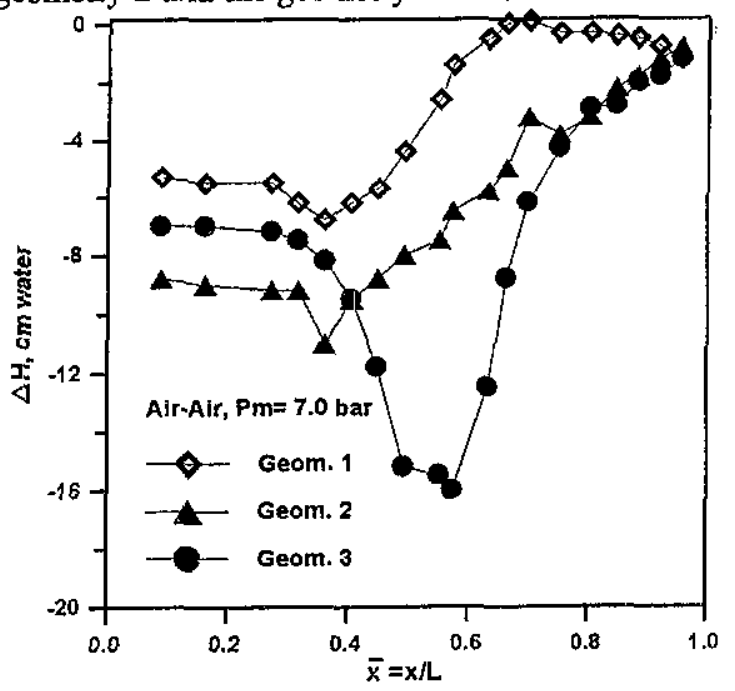

Figure (6) Effect of ejector geometry on the measured static pressure distribution for air-air flow ejector.

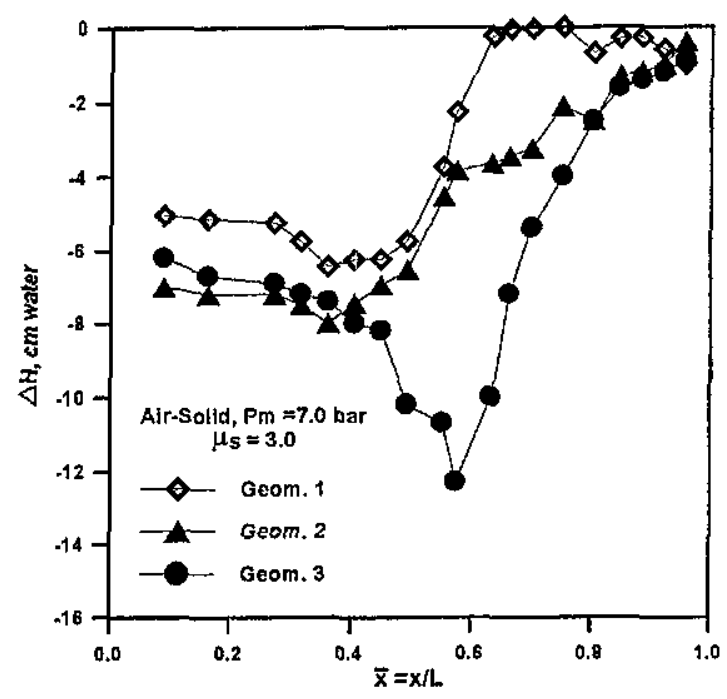

Figure (7) Effect of ejector geometry on the measured static pressure distribution for air-solid flow ejector 
A comparison between the maximum vacuum pressure with the presence of solid particle in figure (7) and without solid particles figure (6) indicates that the vacuum pressure decreases with $7.5 \%$ for geometry-1, $25 \%$ for geometry-2 and $27 \%$ for geometry-3.

\section{2- Effect of Motive Pressure:}

Effect of the motive gas pressure on both measured and calculated axial static pressure distribution for air-air flow ejector is shown in figure ( $)$. Theoretical calculations and experiments are performed for each geometry at three different values of the motive pressure $\left(p_{m}=3,5\right.$ and 7 bar) respectively. It can be seen from figure (8.a) that, increasing the pressure of motive gas for geometry- 1 tends to increase the vacuum pressure along the ejector length. The maximum vacuum is occurred at injection position, where it changes from $-3 \mathrm{~cm}$ water at $\mathrm{p}_{\mathrm{m}}=3$ bar to -7 $\mathrm{cm}$ water at $\mathrm{p}_{\mathrm{m}}=7$ bar. The static pressure increases through the mixing part due to the mixing process to reach zero difference pressure ( $\Delta \mathrm{H}=0.0 \mathrm{~cm}$ water) and the pressure returns to be decreased through the tail pipe due to' friction. figures (8.b) and (8.c) illustrate the effect of the motive pressure on the axial static pressure distributions obtained for geometries 2 and 3 respectively. From the plots of figure (8), it can be noticed that the geometry- 3 has a remarkable effect on pressure difference along the ejector length compared with geometry-1.

Effect of changing the motive gas pressure on the theoretical and experimental results of axial static pressure distribution for air-solid flow ejector is given in figure (9). Similar behaviour for the pressure distribution is shown in air-solid as previously obtained for air-air ejector. Also, the results show a reasonable agreement between the theoretical and experimental results. Furthermore, results of figure (9) reveal that the maximum vacuum pressure decreases due to presence of solid for three tested geometries. Generally, it can be concluded that increasing the motive gas pressure tends to increase the velocities of both the sucked air and solid particles, and consequently to increase also the sucked rate of solid particles.

\section{3- Effect of Solids Mass Flow Rate:}

Some experiments are performed for each geometry at different values of the solids mass rate ratio $\left(\mu_{s}\right)$. These experiments are carried out to declare the effect of the solids mass flow rate on the axial static pressure.

Figure (10) depicts the effect of solids mass flow rate on the measured wall static pressure for geometry-1, at different values of solids mass ratio.
These values are taken as: $\mu_{s}=0.0$ (air-air flow), 1.5 , 3.0 and 4.0 (air-solid flow).

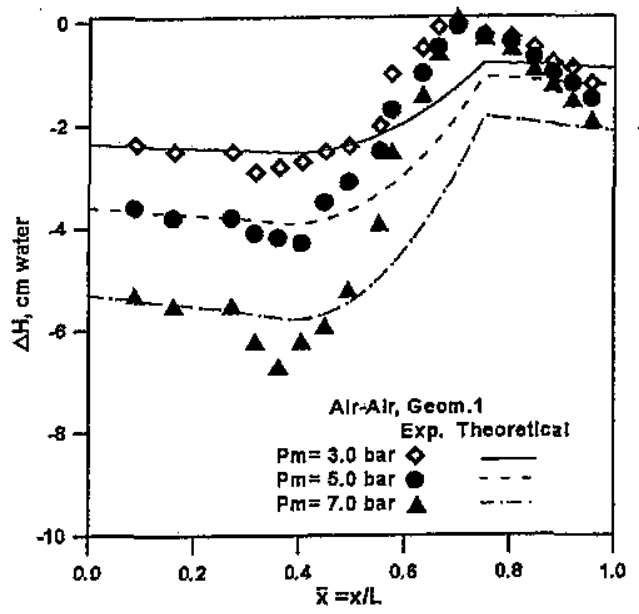

(a)

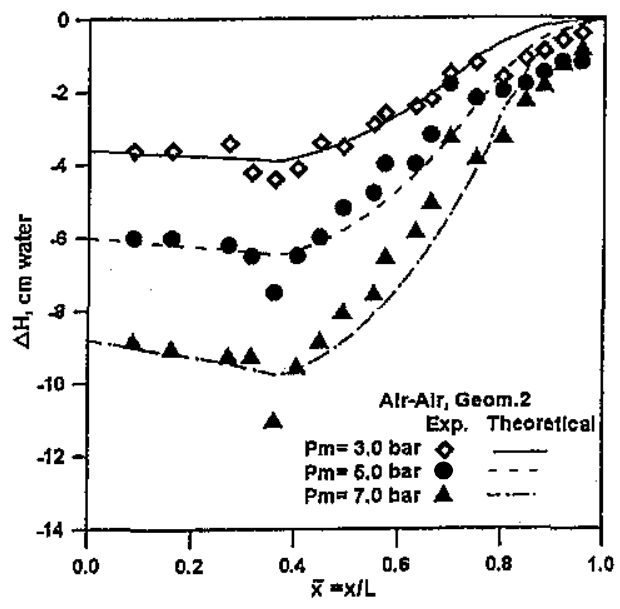

(b)

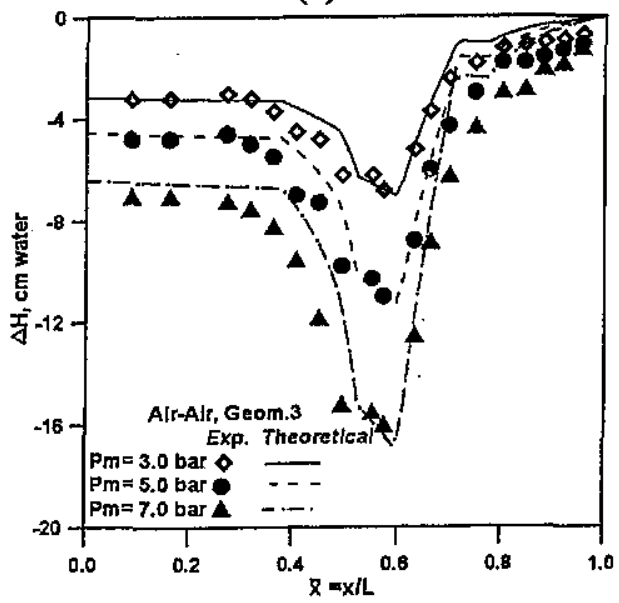

(c)

Figure (8) Effect of motive gas pressure on calculated and measured axial static pressure distribution for air-air ejector.

(a) geometry-1, (b) geometry-2 and (c) geometry-3 


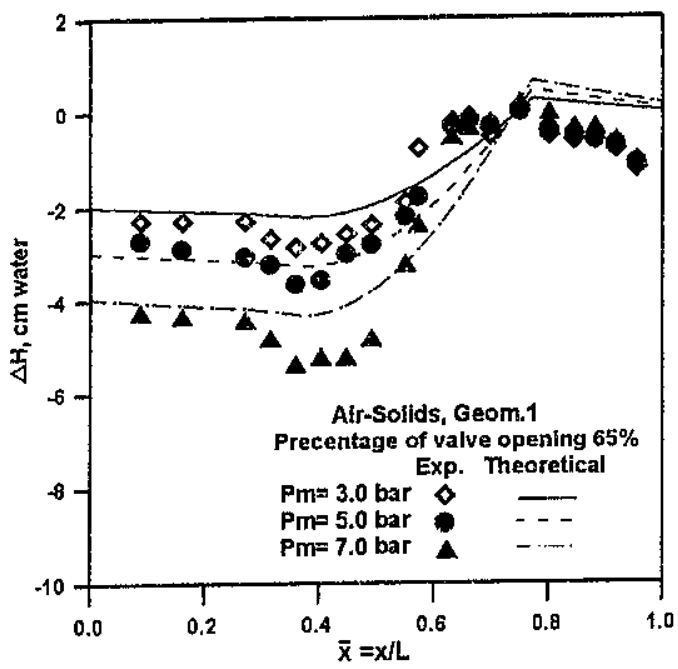

(a)

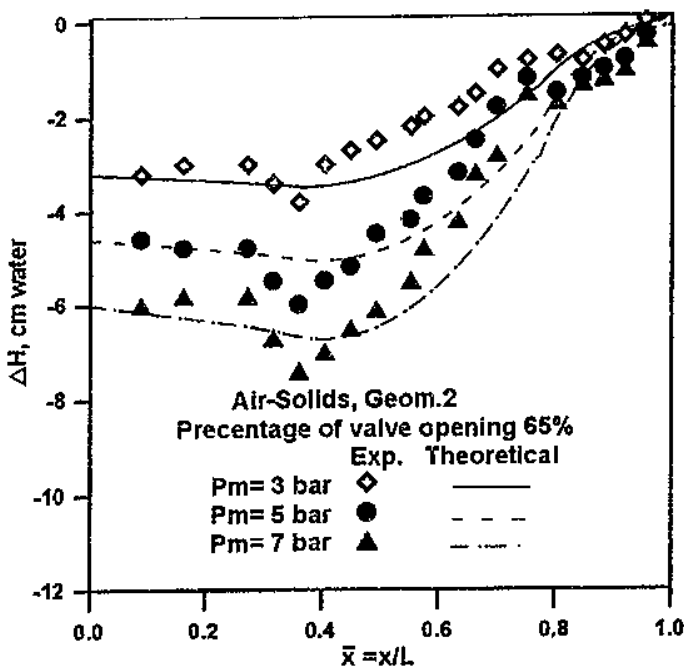

(b)

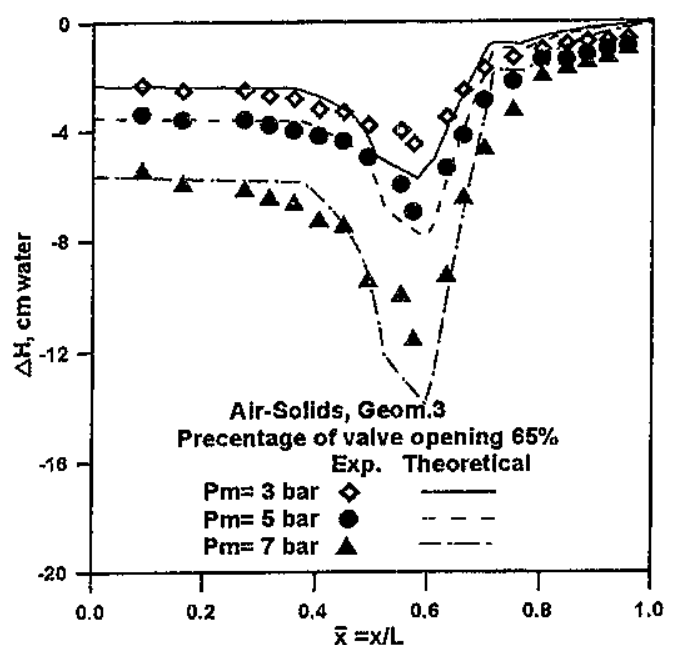

(c)

Figure (9) Effect of motive gas pressure on calculated and measured axial static pressure distribution for air-solid ejector (a) geometry-1, (b) geometry-2 and (c) geometry-3 Results of figure (10) are performed at constant value of the motive gas pressure $\left(p_{m}\right)$ of 7.0 bar. From the figure it can be seen that, increasing solids mass flow ratio decreases the difference pressure (vacuum pressure) along the ejector. It can be noticed also in figure (10) that the air-air flow $\left(\mu_{s}=0.0\right)$ has the maximum vacuum pressure.

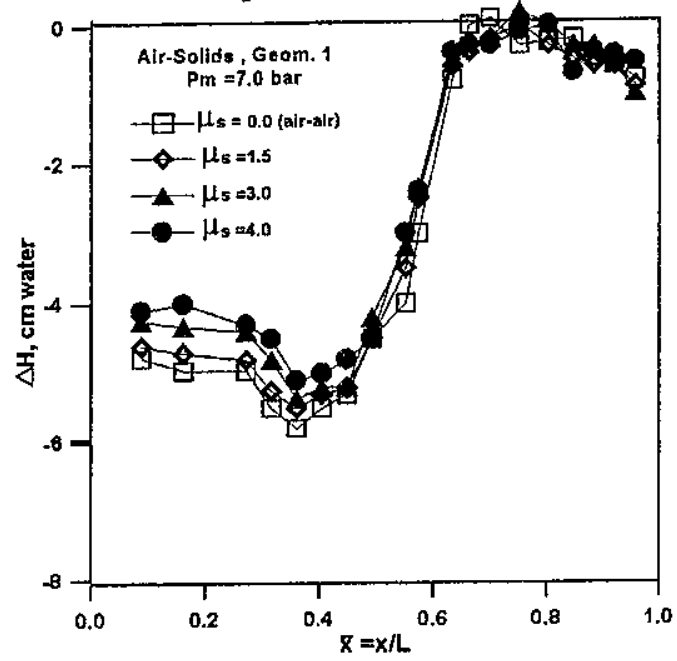

Figure (10) Effect of the solids mass ratio on the measured static pressure distribution for geometry-1.

Effect of solids mass flow rate on the axial static pressure distribution for geometry- 2 at $\mathrm{p}_{\mathrm{m}}=7$ bar is shown in figure (11). It can be illustrated that the single-phase flow $\left(\mu_{\mathrm{s}}=0.0\right)$ has the maximum vacuum pressure $(-11 \mathrm{~cm}$ water). Increasing the solids mass ratio in figure (11) tends to decrease the vacuum pressure. For example, the vacuum pressure becomes $-5.5 \mathrm{~cm}$ water for solids mass ratio equals 6 . Difference of vacuum pressure between single phase and two-phase conditions can be attributed to the fact that geometry-2 sucked higher rate of the solid particles.

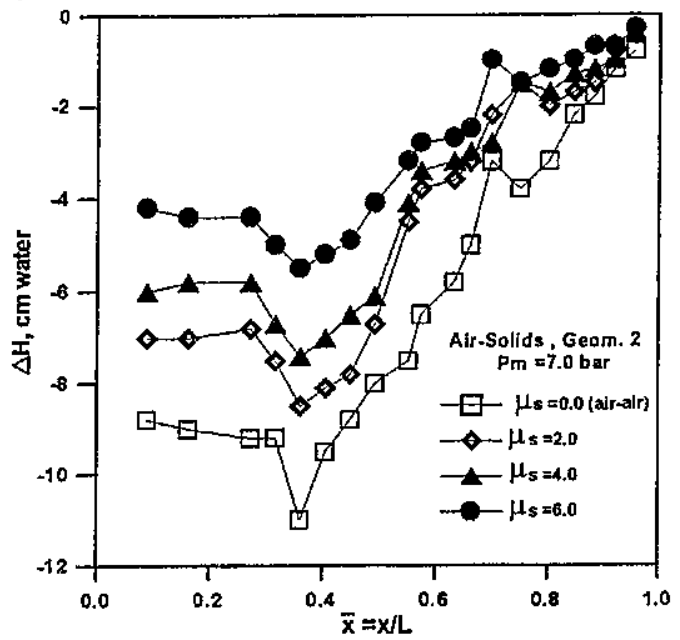

Figure (11) Effect of the solids mass ratio on the measured static pressure distribution for geometry-2 
The pronounced effect of solids flow rate on the axial static pressure distribution along such an ejector can be observed with geometry-3. As shown in figure (12), the maximum vacuum pressure changes from $17 \mathrm{~cm}$ water for air-air flow $\left(\mu_{3}=0.0\right)$ to $-10 \mathrm{~cm}$ water for air-solid flow $\left(\mu_{s}=7.5\right)$. Geometry-3 is preferable because it can sucked large rate from the solid particles at the same operation conditions compared with geometries land 2.

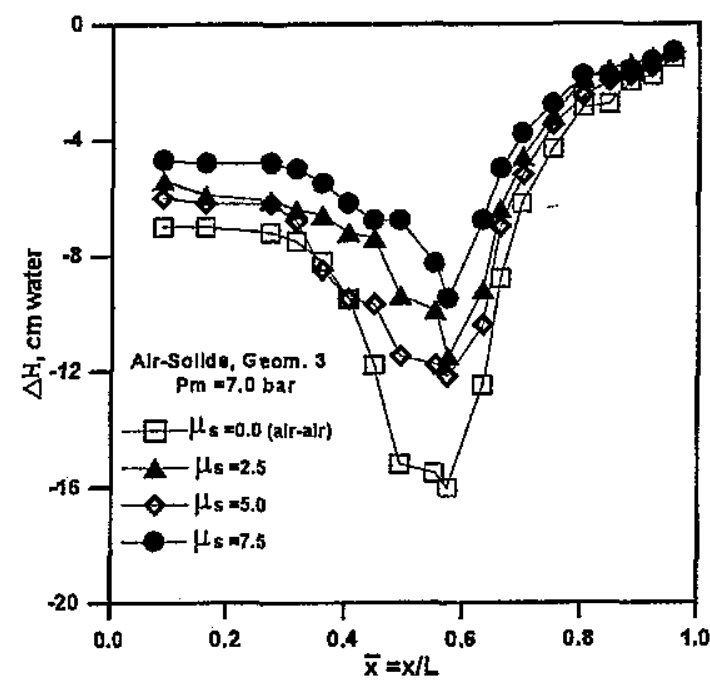

Figure (12) Effect of the solids mass ratio on the measured static pressure distribution for geometry-3

\section{6- CONCLUSIONS}

The main conclusions which are drawn from this study are as follows:

1- The suggested theoretical model is suitable to predict the flow through the ejector.

2- The ejector geometry has a pronouriced effect on the suction mass flow rate and the ejector performance.

3- The suction solid particles flow rate increases with increasing the motive gas pressure.

4- The solid mass flow rate has an opposite effect on the maximum vacuum pressure for the three tested geometries.

\section{NOMENCLATURE}

A Cross section area

$\mathrm{C}_{\mathrm{Ds}}$ Drag coefficient

d Diameter

$\mathrm{m}^{2}$

$-$

DR The ratio of the pipe diameter to the particle diameter

$f_{g} \quad$ Gas-wall friction factor

$f_{p}$ Solid-wall friction factor

$f_{3}$ Drag force per unit volume of particles
$F_{p} \quad$ Solid-wall friction force per unit volume

$\mathrm{N} / \mathrm{m}^{3}$

$F_{w}$. Gas-wall friction force per unit volume

g Acceleration due to gravity

$\mathrm{N} / \mathrm{m}^{3}$

$\mathrm{m} / \mathrm{s}^{2}$

$\mathrm{H}$ Pressure head

cm water

$\Delta \mathrm{H}$ Pressure difference between atmosphere and measured pressure $\Delta \mathrm{H}=\mathrm{H}_{\mathrm{atm}}-\mathrm{H}$

$\mathrm{L}$ Total length of ejector

cm water

$\dot{\mathrm{m}}$ Mass flow rate

$\mathrm{m}$

p Pressure

$\mathrm{kg} / \mathrm{sec}$

$\mathrm{R}$ Gas constant

$\mathrm{Pa}$

$\mathrm{J} / \mathrm{kg} . \mathrm{K}$

$\mathrm{Si}$ Ratio between gas and solid velocities at any section along the ejector length,

$$
\left(\mathrm{Si}=\frac{\mathrm{v}_{\mathrm{g}}}{\mathrm{v}_{\mathrm{s}}}\right)
$$

s Ratio between inlet solid and inlet gas

$$
\text { velocities, }\left(s=\frac{v_{\text {sl }}}{v_{\mathrm{gl}}}\right)
$$

$\mathrm{T}$ Temperature

K

t Time

u Exit motive gas velocity from nozzle

$\mathrm{V}$ Volume

$\mathrm{v}$ Velocity

$x$ Distance along the axis of ejector

$\Delta \mathrm{x}$ Control volume length

S $\mathrm{m} / \mathrm{s}$ $\mathrm{m}^{3}$ $\mathrm{m} / \mathrm{s}$ $\mathrm{m}$

$\mathrm{m}$

\section{Greek symbols}

$\varepsilon \quad$ Gas volume to the total flow volume in gas -solid flow mixture (gas void fraction)

$\eta$ Viscosity of gas

$\mu$ The mass flow ratio, $\mu=\frac{\dot{\mathrm{m}}}{\dot{\mathrm{m}}_{\mathrm{j}}}$

$\rho$ Density

$\lambda$ Density ratio (solid to gas density)

Dimensionless numbers

Ga Galileo number; $\left(\mathrm{Ga}=\frac{\operatorname{gd}_{\mathrm{p}}^{3} \rho_{\mathrm{g}}^{2}}{\eta^{2}}\right)$

$\mathrm{Fr}_{\mathrm{p}}$ Froude number, $\left(\mathrm{Fr}_{\mathrm{p}}=\frac{\mathrm{v}_{\mathrm{s}}^{2}}{\mathrm{gd}_{\mathrm{p}}}\right)$

$F r_{B}$ Froude number, $\left(F r_{g}=\frac{v_{g}^{2}}{g d_{p}}\right.$ )

Re Reynolds number

\section{Subscripts}

a Air

atm Atmosphere condition

g Gas phase

j Injection (motive) gas

o Stagnation condition 
p Particle

r Relative velocity

S Solid phase

$t$ Pipe

1 Inlet condition

\section{REFERENCES}

[1] Engel M. O., "Some problems in the design and operation of jet ejectors", Proc. Instn. Mechanical Engineering, Vol. 177, No. 13, pp. 347-357, 1963.

[2] Hedges K. R. and Hill P. G., "Compressible flow ejectors, Part I-Development of a finitedifference flow model", CSME conference, Montreal, Quebec, Canada, May 13-15, 1974.

[3] Abou-Taleb F. S., " Effect of geometric parameters on the performance of ejectors", M. Sc. Thesis, Faculty of Engineering, Menoufia University, 1986.

[4] Hickman K. E., Hill P. G., and Gilbert G. B., " Analysis and testing high entrainment singlenozzle jet pumps with variable area mixing tubes", NACA Report, No. CR-2067, 1972.

[5] Fabri J. and Paulon J., " Theory and experiments on supersonic air-to-air ejectors" National advisory committee for aeronautics", NACA, Washington, September 1958.

[6] Sazbo S., "Influence of the material quality of primary gas jets on the final vacuum created by a supersonic gas ejector", Journal of Computational and Applied Mechanics, Volume 2., No. 1, pp.131-144, 2001.
[7] Hung B. J., Chang J. M., Wang C. P. and Petrenko V. A., "A 1-D analysis of ejector performance", International Journal of Refrigeration Vol. 22, pp. 354-364, 1999.

[8] Kmiec A., and Leschonski K., " Acceleration of the solid phase during pneumatic conveying in vertical pipes", The Chemical Engineering Journal, Vol. 36, pp. 59-70, 1987.

[9] Kovacs L., and Varadi S., " Two-phase flow in the vertical pipeline of air lift", Periodica Polytechnica Ser. Mech. Eng. Vol. 43, No. 1, pp. 3-18, 1999.

[10] Chellappan S. and Ramaiyan G., " Experimental study design parameters of gas-solid injector feeder", Powder Technology, Vol. 48, pp. 141$144,1986$.

[11] Kmiec A., and Leschonski K., " Analysis of two-phase flows in gas-solids injectors" The Chemical Engineering Journal, Vol. 45, pp. 137147, 1991.

[12] Kmiec A., and Leschonski K., " Numerical calculation methods for solids injectors", Powder Technology, Vol. 95, pp. 75-78, 1998.

[13] Crowe C., Summerfeld M. and Tsuji Y.," The dynamics Multiphase flows with droplets and particles", CRC Press,(1998)

[14] Nakamura S., "Applied numerical methods with software ", Prentice-Hall, Inc. 1991. 